\title{
Estimation under a finite mixture of modified Weibull distributions based on censored data via EM algorithm with application
}

\author{
Saieed F. Ateya ${ }^{1,2, *}$ and Amirah S. Alharthi ${ }^{1, \dagger}$ \\ ${ }^{1}$ Mathematics \& Statistics Department, Faculty of Science \\ Taif University, Taif, Saudi Arabia, \\ ${ }^{2}$ Mathematics Department, Faculty of Science, Assiut University, Egypt \\ Received 2 March 2014 \\ Accepted 27 Augustus 2014
}

\begin{abstract}
In this paper, the maximum likelihood estimates (MLE's) of the parameters of a finite mixture of modified Weibull (MW $(\alpha, \beta, \gamma)$ ) distributions are obtained based on type-I and type-II censored samples using the EM algorithm. A simulation study is carried out to study the behavior of the mean squared errors. A real data set is introduced and analyzed using a mixture of two MW distributions and also using a mixture of two Weibull $(\alpha, \beta)$ distributions. A comparison is carried out between the mentioned mixtures based on the corresponding Kolmogorov-Smirnov (K-S) test statistic to emphasize that the MW mixture model fits the data better than the other mixture model.
\end{abstract}

Keywords: Modified Weibull Distribution, Maximum likelihood estimation, EM algorithm, Finite mixture models, Weibull distribution, type-I censoring, type-II censoring, Kolmogorov-Smirnov (KS) test statistic.

MSA 2010: 62H12, 62N01, 62N05

\footnotetext{
E-mail address: said_f_atya@yahoo.com

'E-mail address: a_s_j_h@@ @otmail.com
} 


\section{Introduction}

In 1939 the Swedish engineer Walloddi Weibull published two papers on the strength of material in a series edited by the Royal Swedish Institute for Engineering Research. In the first paper [1], the distribution function is introduced and in the second paper [2], the moments of this distribution along with graphical and tabular aids and the estimates of the parameters are obtained. Many applications in industrial quality control are discussed in Berrettoni [3]. A certain generalization of the Weibull distribution is described in Mudholkar et al.[4] and applied to survival data. Exact coverage probabilities of approximate prediction intervals for the number of failures to be observed in a future inspection of a sample are evaluated in Nordman and Meeker [5]. Various distributional aspects of Weibull distribution is investigated in several recent papers. For instance, products and ratios of Weibull random variables is studied by Nadarajah and Kotz [6]. Lieblein and Zelen [7], Kao [8], Mann [9], Nelson [10], Whittemore and Altschuler [11], Calabria and Pulcini [12], Mittnik and Reachev [13], Jiang et al. [14] and Abo-Eleneen [15] among others, utilized the Weibull distribution in their works.

The book by Rinne [16] covers the Weibull distribution in many of its aspects starting from the history, properties, developments and applications up to the most recent research done in the subject matter, to the date of the book's publication.

The modified Weibull distribution was proposed by Lai et al. [17] as a new lifetime distribution. They have shown the capability of the model for modeling a bathtub shped hazard rate function. In addition, they characterized the model through the Weibull plot paper. Further, they showed that the modified Weibull model compares well with other competing models to fit data that exhibit a bathtub shaped hazard rate

function. Sultan [18] studied the record values from the modified Weibull distribution and studied its applications. Vasile et al. [19] used the Bayes method to estimate the parameters of the modified Weibull distribution.

The probability density function (pdf), the cumulative distribution function (cdf), the survival function (sf) and the hazard rate function (hrf) of the $\operatorname{MW}(\alpha, \beta, \gamma)$ distribution are given, respectively, by

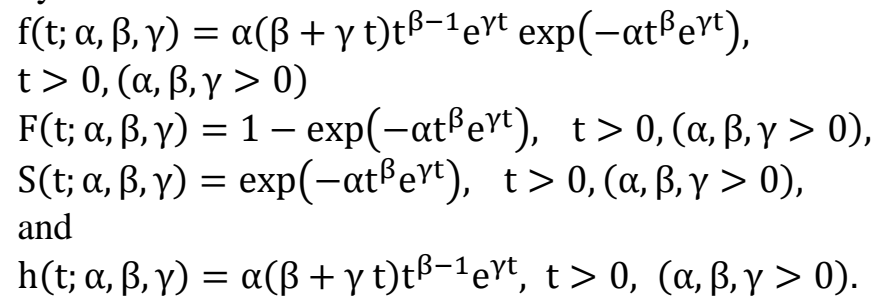

$\mathrm{h}(\mathrm{t} ; \alpha, \beta, \gamma)=\alpha(\beta+\gamma \mathrm{t}) \mathrm{t}^{\beta-1} \mathrm{e}^{\gamma \mathrm{t}}, \mathrm{t}>0,(\alpha, \beta, \gamma>0)$.

Here $\alpha$ is a scale parameter and $\beta$ and $\gamma$ are shape parameters.

The (MW distributions) given in (1.1) is a limiting distribution of the beta-integrated model, see Lai et al. [20], and it is related to the following well-known distributions:

1.At $\gamma=0$, MW distributions reduces to the two-parameter Weibull distribution.

2. At $\beta=0$, MW distributions reduces to a type I extreme-value distribution and is also known as a log-gamma distribution or log-Weibull distribution, see Johnson et al. [21].

A random variable $\mathrm{T}$ is said to have a finite mixture of MW distributions with parameters $\theta_{j}=\left(\alpha_{j}, \beta_{j}, \gamma_{j}\right), j=1,2, \ldots, k$, if its pdf is given by

$\mathrm{f}(\mathrm{t} ; \theta)=\sum_{\mathrm{j}=1}^{\mathrm{k}} \mathrm{p}_{\mathrm{j}} \mathrm{f}_{\mathrm{j}}\left(\mathrm{t} ; \theta_{\mathrm{j}}\right)$,

where $\theta=\left(\theta_{1}, \theta_{2}, \ldots, \theta_{k}, p_{1}, \ldots, p_{k}\right)$,

$\mathrm{f}_{\mathrm{j}}\left(\mathrm{t} ; \theta_{\mathrm{j}}\right)=\alpha_{\mathrm{j}}\left(\beta_{\mathrm{j}}+\gamma_{\mathrm{j}} \mathrm{t}\right) \mathrm{t}^{\beta_{j}-1} \mathrm{e}^{\gamma_{\mathrm{j}} \mathrm{t}} \exp \left(-\alpha_{\mathrm{j}} \mathrm{t}^{\beta_{\mathrm{j}}} \mathrm{e}^{\gamma_{\mathrm{j}} \mathrm{t}}\right)$, 
$\mathrm{t}>0,\left(\alpha_{\mathrm{j}}, \beta_{\mathrm{j}}, \gamma_{\mathrm{j}}>0\right), \mathrm{p}_{\mathrm{j}} \geq 0, \sum_{\mathrm{J}=1}^{\mathrm{k}} \mathrm{p}_{\mathrm{j}}=1$.

The corresponding cdf, sf and hrf are given by

$\mathrm{F}(\mathrm{t} ; \theta)=\sum_{\mathrm{j}=1}^{\mathrm{k}} \mathrm{p}_{\mathrm{j}} \mathrm{F}_{\mathrm{j}}\left(\mathrm{t} ; \theta_{\mathrm{j}}\right), \mathrm{F}_{\mathrm{j}}\left(\mathrm{t} ; \theta_{\mathrm{j}}\right)=1-\exp \left(-\alpha_{\mathrm{j}} \mathrm{t}^{\beta_{\mathrm{j}}} \mathrm{e}^{\gamma_{\mathrm{j}} \mathrm{t}}\right)$,

$\mathrm{S}(\mathrm{t} ; \theta)=\sum_{\mathrm{j}=1}^{\mathrm{k}} \mathrm{p}_{\mathrm{j}} \mathrm{S}_{\mathrm{j}}\left(\mathrm{t} ; \theta_{\mathrm{j}}\right), \quad \mathrm{S}_{\mathrm{j}}\left(\mathrm{t} ; \theta_{\mathrm{j}}\right)=\exp \left(-\alpha_{\mathrm{j}} \mathrm{t}^{\beta_{\mathrm{j}}} \mathrm{e}^{\gamma_{\mathrm{j}} \mathrm{t}}\right)$,

$\mathrm{h}(\mathrm{t} ; \theta)=\frac{\mathrm{f}(\mathrm{t} ; \theta)}{\mathrm{s}(\mathrm{t} ; \theta)}$.

\section{Maximum likelihood estimation based on Type-I censored data}

Suppose that we have $n$ items from a finite mixture of MW distributions $\left(\alpha_{j}, \beta_{j}, \gamma_{j}\right), j=1,2, \ldots, k$. All items are put on a life testing experiment. Suppose that $r$ units have failed during the interval $\left(0, t_{0}\right)$ and $(n-r)$ units are still active, where $t_{0}$ is a predetermined time. Let $t_{1}, \ldots, t_{n}$ be a random sample from the mixed population. The exact lifetime of an item will be observed only if $t_{i} \leq t_{0}, i=$ $1,2, \ldots, \mathrm{n}$. This is known as type-I censored sample. The likelihood function based on type-I censored sample, see Lawless [22], may be written as

$\mathrm{L}(\theta ; \mathrm{t}) \propto \prod_{\mathrm{i}=1}^{\mathrm{n}}\left[\mathrm{f}\left(\mathrm{t}_{\mathrm{i}} ; \theta_{\mathrm{j}}\right)\right]^{\delta_{\mathrm{i}}}\left[\mathrm{S}\left(\mathrm{t}_{0} ; \theta_{\mathrm{j}}\right)\right]^{1-\delta_{\mathrm{i}}}$,

Where $f\left(t_{i}\right)$ and $S\left(t_{0}\right)$ are defined in (1.4) and (1.6) after replacing $t$ by $t_{i}$ and $t_{0}$ respectively, $t=$ $\left(\mathrm{t}_{1}, \mathrm{t}_{2}, \ldots, \mathrm{t}_{\mathrm{n}}\right)$ and $\delta_{\mathrm{i}}$ is an indicator function, given by

$\delta_{\mathrm{i}}= \begin{cases}1 & , \mathrm{t}_{\mathrm{i}} \leq \mathrm{t}_{0}, \\ 0 & , \mathrm{t}_{\mathrm{i}}>\mathrm{t}_{0} .\end{cases}$

The natural logarithm of (2.1) is given by

$\log [\mathrm{L}(\theta ; \mathrm{t})]=\log \mathrm{a}+\sum_{\mathrm{i}=1}^{\mathrm{n}}\left[\delta_{\mathrm{i}} \log \mathrm{f}\left(\mathrm{t}_{\mathrm{i}} ; \theta_{\mathrm{j}}\right)+\left(1-\delta_{\mathrm{i}}\right) \log \mathrm{S}\left(\mathrm{t}_{0} ; \theta_{\mathrm{j}}\right)\right]$,

where $\mathrm{a}$ is a constant.

It is well known that the maximum likelihood estimate of the vector of parameters $\left(\alpha_{1}, \alpha_{2}, \beta_{1}, \beta_{2}, \gamma_{1}, \gamma_{2}, p\right)$ are the values of the parameters which maximize the likelihood function (2.1) or the logarithm of the likelihood function (2.2). We can see that the log-likelihood function is difficult to maximize because it contains the log of the sum.

The EM algorithm, suggested by Dempster, et al [23] and explained by McLachlan and Krishnan [24], making use of the concept of missing data. In this case, the missing data is the knowledge of which group each observation in the sample comes from. These missing data can be represented by the random vector $\mathrm{Z}=\left(\mathrm{Z}_{1}, \mathrm{Z}_{2}, \ldots, \mathrm{Z}_{\mathrm{n}}\right)$, where $\mathrm{Z}_{\mathrm{i}}=\left(\mathrm{Z}_{\mathrm{i} 1}, \mathrm{Z}_{\mathrm{i} 2}, \ldots, \mathrm{Z}_{\mathrm{ik}}\right), \mathrm{i}=1,2, \ldots, \mathrm{n}$ and

$\mathrm{Z}_{\mathrm{ij}}= \begin{cases}1 & \text { if } \mathrm{T}_{\mathrm{i}} \text { belongs to group } \mathrm{j}, \\ 0 & \text { otherwise. }\end{cases}$

Based on $\mathrm{T}=\left(\mathrm{T}_{1}, \mathrm{~T}_{2}, \ldots, \mathrm{T}_{\mathrm{n}}\right)$ and $\mathrm{Z}$, the complete data likelihood function will be in the form

$\mathrm{L}_{\mathrm{C}}(\theta ; \mathrm{t}, \mathrm{z})=\prod_{\mathrm{i}=1}^{\mathrm{n}} \prod_{\mathrm{j}=1}^{\mathrm{k}}\left\{\left[\mathrm{p}_{\mathrm{j}} \mathrm{f}_{\mathrm{j}}\left(\mathrm{t}_{\mathrm{i}} ; \theta_{\mathrm{j}}\right)\right]^{\mathrm{z}_{\mathrm{ij}} \delta_{\mathrm{i}}}\left[\mathrm{p}_{\mathrm{j}} \mathrm{S}_{\mathrm{j}}\left(\mathrm{t}_{0} ; \theta_{\mathrm{j}}\right)\right]^{\mathrm{z}_{\mathrm{ij}}\left(1-\delta_{\mathrm{i}}\right)}\right\}$

The EM algorithm consists of two steps:

The E-step requires the calculation of $Q\left(\theta ; \theta^{0}\right)=E_{\theta^{0}}\left[\log \mathrm{L}_{C}(\theta ; \mathrm{T})\right]$, where $\theta^{0}$ is an initial value,

The M-step requires to maximize the function $Q\left(\theta ; \theta^{0}\right)$ to obtain the maximum likelihood estimate of $\theta$.

In our mixture model, the E- and M- steps can be summarized as follows:

E-step: The function $Q\left(\theta ; \theta^{0}\right)$ can be written in the form

$\mathrm{Q}\left(\theta ; \theta^{0}\right)=$

$\sum_{\mathrm{i}=1}^{\mathrm{n}} \sum_{\mathrm{j}=1}^{\mathrm{k}}\left[\log \left(\mathrm{p}_{\mathrm{j}}\right) \mathrm{E}_{\theta^{0}}\left[\mathrm{Z}_{\mathrm{ij}} ; \mathrm{T}_{\mathrm{i}}=\mathrm{t}_{\mathrm{i}}\right]+\right.$

$\left.\delta_{\mathrm{i}} \log \left[\mathrm{f}_{\mathrm{j}}\left(\mathrm{t}_{\mathrm{i}} ; \theta_{\mathrm{j}}\right)\right] \mathrm{E}_{\theta^{0}}\left[\mathrm{Z}_{\mathrm{ij}} ; \mathrm{T}_{\mathrm{i}}=\mathrm{t}_{\mathrm{i}}\right]+\left(1-\delta_{\mathrm{i}}\right) \log \left[\mathrm{S}_{\mathrm{j}}\left(\mathrm{t}_{0} ; \theta_{\mathrm{j}}\right)\right] \mathrm{E}_{\theta^{0}}\left[\mathrm{Z}_{\mathrm{ij}} ; \mathrm{T}_{\mathrm{i}}=\mathrm{t}_{0}\right]\right]$, 
where

$E_{\theta^{0}}\left[Z_{i j} ; T_{i}=t_{i}\right]= \begin{cases}\frac{p_{j}^{0} f_{j}\left(t_{i} ; \theta_{j}^{0}\right)}{\sum_{l=1}^{k}\left[p_{1}^{0} f_{l}\left(t_{i} ; \theta_{l}^{0}\right)\right]}, & t_{i}<t_{0}, \\ \frac{p_{j}^{0} s_{j}\left(t_{i} ; \theta_{j}^{0}\right)}{\sum_{l=1}^{k}\left[p_{l}^{0} s_{l}\left(t_{i} ; \theta_{l}^{0}\right)\right]}, & t_{i}=t_{0} .\end{cases}$

M-step: Maximizing the function $\mathrm{Q}\left(\theta ; \theta^{0}\right)$ and for $\mathrm{j}=1,2, \ldots, \mathrm{k}$, we get

$\hat{\mathrm{p}}_{\mathrm{j}}=\frac{1}{\mathrm{n}}\left[\sum_{\mathrm{i}=1}^{\mathrm{n}}\left[\delta_{\mathrm{i}} \mathrm{p}_{\mathrm{j}}^{0} \mathrm{~A}_{\mathrm{j}}\left(\mathrm{t}_{0} ; \theta_{\mathrm{j}}^{0}\right)+\left(1-\delta_{\mathrm{i}}\right) \mathrm{p}_{\mathrm{j}}^{0} \mathrm{~B}_{\mathrm{j}}\left(\mathrm{t}_{0} ; \theta_{\mathrm{j}}^{0}\right)\right]\right]$,

$\hat{\theta}_{\mathrm{j}}=\arg \max _{\theta_{\mathrm{j}}} \mathrm{W}\left(\theta_{\mathrm{j}} ; \theta_{\mathrm{j}}^{0}\right)$,

where

$\mathrm{W}\left(\theta_{\mathrm{j}} ; \theta_{\mathrm{j}}^{0}\right)=\sum_{\mathrm{i}=1}^{\mathrm{n}}\left\{\delta_{\mathrm{i}} \mathrm{p}_{\mathrm{j}}^{0} \mathrm{~A}_{\mathrm{j}}\left(\mathrm{t}_{\mathrm{i}} ; \theta_{\mathrm{j}}^{0}\right)\left[\log \alpha_{\mathrm{j}}+\log \left(\beta_{\mathrm{j}}+\gamma_{\mathrm{j}} \mathrm{t}_{\mathrm{i}}\right)+\log \left(\mathrm{t}_{\mathrm{i}} \beta_{\mathrm{j}}-1\right)+\gamma_{\mathrm{j}} \mathrm{t}_{\mathrm{i}}-\alpha_{\mathrm{j}} \mathrm{t}_{\mathrm{i}} \beta_{\mathrm{j}} \mathrm{e}^{\gamma_{\mathrm{j}} \mathrm{t}_{\mathrm{i}}}\right]+\right.$ $\left.\left(1-\delta_{\mathrm{i}}\right) \mathrm{p}_{\mathrm{j}}^{0} \mathrm{~B}_{\mathrm{j}}\left(\mathrm{t}_{0} ; \theta_{\mathrm{j}}^{0}\right)\left[-\alpha_{\mathrm{j}} \mathrm{t}_{0} \beta_{\mathrm{j}} \mathrm{e}^{\gamma_{\mathrm{j}} \mathrm{t}_{0}}\right]\right\}$,

$\mathrm{A}_{\mathrm{j}}\left(\mathrm{t}_{\mathrm{i}} ; \theta_{\mathrm{j}}^{0}\right)=\frac{\mathrm{f}_{\mathrm{j}}\left(\mathrm{t}_{\mathrm{i}} ; \theta_{\mathrm{j}}^{0}\right)}{\sum_{\mathrm{l}=1}^{\mathrm{k}}\left[\mathrm{p}_{1}^{0} \mathrm{f}_{\mathrm{l}}\left(\mathrm{t}_{\mathrm{i}} ; \theta_{1}^{0}\right)\right]}$ and $\mathrm{B}_{\mathrm{j}}\left(\mathrm{t}_{0} ; \theta_{\mathrm{j}}^{0}\right)=\frac{\mathrm{s}_{\mathrm{j}}\left(\mathrm{t}_{0} ; \theta_{\mathrm{j}}^{0}\right)}{\sum_{\mathrm{l}=1}^{\mathrm{k}}\left[\mathrm{p}_{1}^{0} \mathrm{~s}_{\mathrm{l}}\left(\mathrm{t}_{0} ; \theta_{\mathrm{l}}^{0}\right)\right]}$.

are constants.

The maximum likelihood estimates (MLE's) of the parameters can be obtained by differentiating (2.9) with respect to the parameters $\alpha_{1}, \alpha_{2}, \beta_{1}, \beta_{2}, \gamma_{1}$ and $\gamma_{2}$, equating to zero and solving the resulting nonlinear equations using Mathematica 9.

\section{Maximum Likelihood Estimation Based on Type-II Censored Data}

Assume that we put $\mathrm{n}$ items from a finite mixture of MW distributions $\left(\alpha_{j}, \beta_{j}, \gamma_{j}\right), j=$ $1,2, \ldots, \mathrm{k}$, components in a life testing experiment. Instead of continuing until all $\mathrm{n}$ items have failed, the experiment is terminated at the time of the $\mathrm{r}^{\text {th }}$ item failure. Such test can save time and money, since it could take a very long time for all items to fail.

Suppose that $t_{1}<t_{2}<\cdots<t_{r}$ is a censored data of size $r$ obtained from a life test on $n$ items (type-II censored data) whose life times have a finite mixture of MW distributions. The likelihood function based on type-II censored data, see Lawless[22], is given by

$\mathrm{L}(\theta ; \mathrm{t})=\frac{\mathrm{n} !}{(\mathrm{n}-\mathrm{r}) !}\left[\prod_{\mathrm{i}=1}^{\mathrm{r}} \mathrm{f}\left(\mathrm{t}_{\mathrm{i}} ; \theta_{\mathrm{j}}\right)\left[\mathrm{S}\left(\mathrm{t}_{\mathrm{r}} ; \theta_{\mathrm{j}}\right)\right]^{\mathrm{n}-\mathrm{r}}\right.$.

This likelihood can be also written in the form

$\mathrm{L}(\theta ; \mathrm{t})=\frac{\mathrm{n} !}{(\mathrm{n}-\mathrm{r}) !}\left[\prod_{\mathrm{i}=1}^{\mathrm{n}} \mathrm{f}\left(\mathrm{t}_{\mathrm{i}} ; \theta_{\mathrm{j}}\right)^{\delta_{\mathrm{i}}}\right]\left[\mathrm{S}\left(\mathrm{t}_{\mathrm{r}} ; \theta_{\mathrm{j}}\right)^{1-\delta_{\mathrm{i}}}\right]$,

$\delta_{1}=\ldots=\delta_{\mathrm{r}}=1, \delta_{\mathrm{r}+1}=\ldots=\delta_{\mathrm{n}}=0$.

The natural logarithm of (3.2) is given by

$\log [\mathrm{L}(\theta ; \mathrm{t})]=\log \left\{\frac{\mathrm{n} !}{(\mathrm{n}-\mathrm{r}) !}\right\}+\sum_{\mathrm{i}=1}^{\mathrm{n}}\left[\delta_{\mathrm{i}} \log \left[\mathrm{f}\left(\mathrm{t}_{\mathrm{i}} ; \theta_{\mathrm{j}}\right)\right]+\left(1-\delta_{\mathrm{i}}\right) \log \left[\mathrm{S}\left(\mathrm{t}_{\mathrm{r}} ; \theta_{\mathrm{j}}\right)\right]\right.$.

The maximum likelihood estimate of the vector of parameters $\theta$ is the value which maximize the loglikelihood function in (3.3). Since the log-likelihood function contains the log of the sum so that it will be difficult to maximize.

Using the same missing data represented by the random vector $\mathrm{Z}=\left(\mathrm{Z}_{1}, \ldots, \mathrm{Z}_{\mathrm{n}}\right)$, where $\mathrm{Z}_{\mathrm{i}}=$ $\left(Z_{i 1}, Z_{i 2}, \ldots, Z_{i k}\right), i=1,2, \ldots, n$, which defined in the previous case, the complete data likelihood function will be in the form

$\mathrm{L}_{\mathrm{C}}(\theta ; \mathrm{t}, \mathrm{z})=\frac{\mathrm{n} !}{(\mathrm{n}-\mathrm{r}) !} \prod_{\mathrm{i}=1}^{\mathrm{n}} \prod_{\mathrm{j}=1}^{\mathrm{k}}\left\{\left[\mathrm{p}_{\mathrm{j}} \mathrm{f}_{\mathrm{j}}\left(\mathrm{t}_{\mathrm{i}} ; \theta_{\mathrm{j}}\right)\right]^{\mathrm{z}_{\mathrm{ij}} \delta_{\mathrm{i}}}\left[\mathrm{p}_{\mathrm{j}} \mathrm{S}_{\mathrm{j}}\left(\mathrm{t}_{\mathrm{r}} ; \theta_{\mathrm{j}}\right)\right]^{\mathrm{z}_{\mathrm{ij}}\left(1-\delta_{\mathrm{i}}\right)}\right\}$.

The E- and M- steps can be summarized as follows: 
E-step: The function $Q\left(\theta ; \theta^{0}\right)$ is in the form

$$
\begin{aligned}
\mathrm{Q}\left(\theta ; \theta^{0}\right)=\log & \left\{\frac{n !}{(n-r) !}\right\} \\
& +\sum_{\mathrm{i}=1}^{\mathrm{n}} \sum_{\mathrm{j}=1}^{\mathrm{k}}\left[\log \left(\mathrm{p}_{\mathrm{j}}\right) \mathrm{E}_{\theta^{0}}\left[\mathrm{Z}_{\mathrm{ij}} ; \mathrm{T}_{\mathrm{i}}=\mathrm{t}_{\mathrm{i}}\right]\right. \\
& \left.+\delta_{\mathrm{i}} \log \left[\mathrm{f}_{\mathrm{j}}\left(\mathrm{t}_{\mathrm{i}} ; \theta_{\mathrm{j}}\right)\right] \mathrm{E}_{\theta^{0}}\left[\mathrm{Z}_{\mathrm{ij}} ; \mathrm{T}_{\mathrm{i}}=\mathrm{t}_{\mathrm{i}}\right]+\left(1-\delta_{\mathrm{i}}\right) \log \left[\mathrm{S}_{\mathrm{j}}\left(\mathrm{t}_{\mathrm{r}} ; \theta_{\mathrm{j}}\right)\right] \mathrm{E}_{\theta^{0}}\left[\mathrm{Z}_{\mathrm{ij}} ; \mathrm{T}_{\mathrm{i}}=\mathrm{t}_{\mathrm{r}}\right]\right]
\end{aligned}
$$

where

$E_{\theta^{0}}\left[Z_{i j} ; T_{i}=t_{r}\right]= \begin{cases}\frac{p_{j}^{0} f_{j}\left(t_{i} ; \theta_{j}^{0}\right)}{\sum_{l=1}^{k}\left[p_{1}^{0} f_{l}\left(t_{i} ; \theta_{1}^{0}\right)\right]}, & t_{i}<t_{r}, \\ \frac{p_{j}^{0} s_{j}\left(t_{i j} ; \theta_{j}^{0}\right)}{\sum_{l=1}^{k}\left[p_{1}^{0} s_{l}\left(t_{i} ; \theta_{l}^{0}\right)\right]}, & t_{i}=t_{r} .\end{cases}$

M-step: Maximizing the function $Q\left(\theta ; \theta^{0}\right)$ and for $j=1,2, \ldots, k$, we get

$\hat{p}_{j}=\frac{1}{n}\left[\sum_{i=1}^{r} p_{j}^{0} A_{j}\left(t_{i} ; \theta_{j}^{0}\right)+(n-r) p_{j}^{0} D_{j}\left(t_{r} ; \theta_{j}^{0}\right)\right]$,

$\hat{\theta}_{\mathrm{j}}=\arg \max _{\theta_{\mathrm{j}}} \mathrm{Y}\left(\theta_{\mathrm{j}} ; \theta_{\mathrm{j}}^{0}\right)$,

where

$\mathrm{Y}\left(\theta_{\mathrm{j}} ; \theta_{\mathrm{j}}^{0}\right)=\sum_{\mathrm{i}=1}^{\mathrm{r}}\left\{\mathrm{p}_{\mathrm{j}}^{0} \mathrm{~A}_{\mathrm{j}}\left(\mathrm{t}_{\mathrm{i}} ; \theta_{\mathrm{j}}^{0}\right)\left[\log \alpha_{\mathrm{j}}+\log \left(\beta_{\mathrm{j}}+\gamma_{\mathrm{j}} \mathrm{t}_{\mathrm{i}}\right)+\log \left(\mathrm{t}_{\mathrm{i}} \beta_{\mathrm{j}}-1\right)+\gamma_{\mathrm{j}} \mathrm{t}_{\mathrm{i}}-\alpha_{\mathrm{j}} \mathrm{t}_{\mathrm{i}} \beta_{\mathrm{j}} \mathrm{e}^{\gamma_{\mathrm{j}}} \mathrm{t}_{\mathrm{i}}\right]+(\mathrm{n}-\right.$ r) $\left.p_{j}^{0} D_{j}\left(t_{r} ; \theta_{j}^{0}\right)\left[-\alpha_{j} t_{r} \beta_{j} e^{\gamma_{j} t_{r}}\right]\right\}$,

and $D_{j}\left(t_{r} ; \theta_{j}^{0}\right)=\frac{s_{j}\left(t_{r} ; \theta_{j}^{0}\right)}{\sum_{l=1}^{k}\left[p_{1}^{0} s_{l}\left(t_{r} ; \theta_{l}^{0}\right)\right]}$.

Differentiating (3.9) with respect to all unknown parameters, then equating to zero and solving the resulting nonlinear equations, the MLE's of all parameters are obtained.

The E- and M-steps, in our two cases, are alternated repeatedly until the difference $L\left(\theta^{s+1} \mid \mathrm{t}\right)-$ $\mathrm{L}\left(\theta^{s} \mid \mathrm{t}\right)$ changes by an arbitrary small amount in the case of convergence of the sequence of the likelihood values $\left\{\mathrm{L}\left(\theta^{\mathrm{s}} \mid \mathrm{t}\right)\right\}$ to get the maximum likelihood estimate of $\theta$, denoted by $\hat{\theta}$.

\section{Results and Discussion}

In this section, a simulation study is carried out to study the behavior of the mean squared errors (MSE's), also a data analysis is introduced. Finally, conclusions and remarks are written.

\subsection{Simulation study}

In case of $j=2$, we can write $p_{1}=p, p_{2}=1-p_{1}$, then the vector of all parameters will be in the form $\theta=\left(\alpha_{1}, \alpha_{2}, \beta_{1}, \beta_{2}, \gamma_{1}, \gamma_{2}, p\right)$. For different populations and different values of $t_{0}$ and $r$ we follow the following steps:

1. Making use of the vector of actual parameters $\theta=\left(\alpha_{1}, \alpha_{2}, \beta_{1}, \beta_{2}, \gamma_{1}, \gamma_{2}, p\right)$, samples of different sizes $n(20,25,30)$ are generated from a mixture of two MW distributions whose pdf given by (1.1) as follows:

- Generate $\mathrm{u}_{1}$ and $\mathrm{u}_{2}$ from the uniform distribution $\mathrm{U}(0,1)$. 
- If $\mathrm{u}_{1}<\mathrm{p}$,

generate from $\mathrm{F}_{1}\left(\mathrm{t} ; \alpha_{1}, \beta_{1}, \gamma_{1}\right)$ using $\mathrm{u}_{2}$, otherwise

generate from $\mathrm{F}_{2}\left(\mathrm{t} ; \alpha_{2}, \beta_{2}, \gamma_{2}\right)$ using $\mathrm{u}_{2}$.

2. For a value $t_{0}$, we consider all values of the random variable $T$ which are less than or equal $t_{0}$ (type-I censored sample).

3. Based on this sample and for different values of $t_{0}$,we can usethe EM algorithm to obtain the maximum likelihood estimate of the vector of parameters $\theta$, denoted by $\hat{\theta}$ as follows

a) Use the vector of the actual parameters as an initial vector $\theta^{0}=\left(\alpha_{1}^{0}, \alpha_{2}^{0}, \beta_{1}^{0}, \beta_{2}^{0}, \gamma_{1}^{0}, \gamma_{2}^{0}, p^{0}\right)$

b) compute $\mathrm{L}\left(\theta^{0} ; \mathrm{t}\right)$,

c) substituting in (2.7) we get $\mathrm{p}^{(1)}$ and solving the maximization problem in (2.8), after replacing $\mathrm{p}^{0}$ by $\mathrm{p}^{(1)}$ we get $\alpha_{1}^{(1)}, \alpha_{2}^{(1)}$, $\beta_{1}^{(1)}, \beta_{2}^{(1)}, \gamma_{1}^{(1)}$ and $\gamma_{2}^{(1)}$,

d) compute $\mathrm{L}\left(\theta^{(1)} ; \mathrm{t}\right)$,

e) substituting by the new vector $\theta^{(1)}=\left(\alpha_{1}^{(1)}, \alpha_{2}^{(1)}, \beta_{1}^{(1)}, \beta_{2}^{(1)}, \gamma_{1}^{(1)}\right.$,

$\left.\gamma_{2}^{(1)}, \mathrm{p}^{(1)}\right)$ in (2.7) we get $\mathrm{p}^{(2)}$ and solving the maximization problem in (2.8) after replacing $\mathrm{p}^{(1)}$ by $\mathrm{p}^{(2)}$ we get $\alpha_{1}^{(2)}, \alpha_{2}^{(2)}, \beta_{1}^{(2)}, \beta_{2}^{(2)}, \gamma_{1}^{(2)}$ and $\gamma_{2}^{(2)}$,

f) compute $\mathrm{L}\left(\theta^{(2)} ; \mathrm{t}\right)$

g) repeating these steps until the difference $L\left(\theta^{s+1} ; t\right)-L\left(\theta^{s} ; t\right)$ will be a small amount, then $\theta^{s+1}$ will be the maximum likelihood estimate of the vector of parameters $\theta$.

4. Based on the sample $t_{1}<t_{2}<\cdots<t_{r}$, which is a Type-II censored sample, we can obtain the EM algorithm, as done in case of type-I censoring, to obtain the maximum likelihood estimate of the same vector of parameters and for different values ofr.

5. Repeat steps 1-4 (m) times for different samples.

6. Compute the mean squared errors(MSE's) of $\hat{\theta}$ over the $m$ as followsMSE $(\hat{\theta})=$ $\frac{1}{m} \sum_{j=1}^{m}\left(\hat{\theta}_{j}-\theta\right)^{2}$, where $\theta$ is the actual value of the vector of parameters.

From Tables (1) and (2) all parameters are estimated based on type-I and type-II censored samples. Sample of sizes 20, 25 and 30 are drawn from a mixture of two MW distributions and the number of repetitions (samples) is $\mathrm{m}=500$. Two censoring values $\mathrm{t}_{0}$ and $\mathrm{r}$ are chosen so as to cover the whole domain of the population in each case. 
Table1: Mean squared errors of the estimates of the parameters $\alpha_{1}, \alpha_{2}, \beta_{1}, \beta_{2}, \gamma_{1}, \gamma_{2}$ and $p$ based on type-I censored data of different sizes $n$, censoring values $t_{0}$ and $\mathrm{m}=500$ repetitions.

$\left(\alpha_{1}=0.7, \alpha_{2}=1.75, \beta_{1}=0.85, \beta_{2}=1.86, \gamma_{1}=1.3, \gamma_{2}=1.2, \mathrm{p}=0.9\right)$

\begin{tabular}{|c|c|c|c|c|c|c|c|c|}
\hline $\mathrm{N}$ & $t_{0}$ & $\operatorname{MSE}(\hat{\mathrm{p}})$ & $\operatorname{MSE}\left(\widehat{\alpha}_{1}\right)$ & $\operatorname{MSE}\left(\widehat{\alpha}_{2}\right)$ & $\operatorname{MSE}\left(\hat{\beta}_{1}\right)$ & $\operatorname{MSE}\left(\hat{\beta}_{2}\right)$ & $\operatorname{MSE}\left(\hat{\gamma}_{1}\right)$ & $\operatorname{MSE}\left(\hat{\gamma}_{2}\right)$ \\
\hline \multirow{4}{*}{20} & 0.4 & 0.0000 & 0.7531 & 1.5462 & 0.2232 & 0.2009 & 0.8081 & 6.24242 \\
\hline & 0.6 & 0.0002 & 0.7283 & 1.8098 & 0.2949 & 0.5285 & 0.92495 & 5.95901 \\
\hline & 0.8 & 0.0005 & 0.4460 & 1.8577 & 0.1563 & 0.8142 & 0.50279 & 4.76797 \\
\hline & 1.0 & 0.0005 & 0.4341 & 1.8252 & 0.1822 & 0.6240 & 0.33495 & 3.36185 \\
\hline \multirow{4}{*}{25} & 0.4 & 0.0000 & 0.6995 & 1.4945 & 0.1949 & 0.1652 & 0.84868 & 5.61466 \\
\hline & 0.6 & 0.0002 & 0.6616 & 1.9304 & 0.2841 & 0.5854 & 0.82375 & 6.71288 \\
\hline & 0.8 & 0.0004 & 0.5035 & 1.7791 & 0.1875 & 0.6758 & 0.48516 & 4.87345 \\
\hline & 1.0 & 0.0004 & 0.4160 & 1.6425 & 0.1442 & 0.5328 & 0.31432 & 3.55471 \\
\hline \multirow{4}{*}{30} & 0.4 & 0.0000 & 0.6998 & 1.6407 & 0.2006 & 0.1717 & 0.77687 & 6.20737 \\
\hline & 0.6 & 0.0002 & 0.6306 & 1.8183 & 0.2506 & 0.5587 & 0.75976 & 6.16546 \\
\hline & 0.8 & 0.0004 & 0.5011 & 1.7851 & 0.1654 & 0.7162 & 0.49228 & 4.76687 \\
\hline & 1.0 & 0.0004 & 0.3047 & 1.7311 & 0.1281 & 0.6820 & 0.23007 & 3.4248 \\
\hline
\end{tabular}

Table2: Mean squared errors of the estimates of the parameters $\alpha_{1}, \alpha_{2}, \beta_{1}, \beta_{2}, \gamma_{1}, \gamma_{2}$ and $p$ based on type-I censored data of different sizes $n$, censoring values $\mathrm{r}$ and $\mathrm{m}=500$ repetitions.

$\left(\alpha_{1}=0.7, \alpha_{2}=1.75, \beta_{1}=0.85, \beta_{2}=1.86, \gamma_{1}=1.3, \gamma_{2}=1.2, \mathrm{p}=0.9\right)$

\begin{tabular}{|c|c|c|c|c|c|c|c|c|}
\hline \multirow{2}{*}{$\mathrm{n}$} & $\mathrm{r}$ & $\operatorname{MSE}(\hat{\mathrm{p}})$ & $\operatorname{MSE}\left(\widehat{\alpha}_{1}\right)$ & $\operatorname{MSE}\left(\widehat{\alpha}_{2}\right)$ & $\operatorname{MSE}\left(\hat{\beta}_{1}\right)$ & $\operatorname{MSE}\left(\hat{\beta}_{2}\right)$ & $\operatorname{MSE}\left(\hat{\gamma}_{1}\right)$ & $\operatorname{MSE}\left(\hat{\gamma}_{2}\right)$ \\
& & & & & & & & \\
\hline \multirow{2}{*}{20} & 15 & 0.0002 & 0.8869 & 1.7285 & 0.3567 & 0.7561 & 0.77045 & 5.11514 \\
\cline { 2 - 10 } & 20 & 0.0000 & 0.0189 & 0.9683 & 0.0081 & 0.1265 & 0.02588 & 0.54406 \\
\hline \multirow{2}{*}{25} & 15 & 0.0001 & 0.7591 & 1.8223 & 0.3154 & 0.4873 & 1.00673 & 4.03009 \\
\cline { 2 - 9 } & 20 & 0.0003 & 0.6679 & 1.7888 & 0.2898 & 0.6275 & 0.58607 & 4.79438 \\
\cline { 2 - 9 } & 25 & 0.0000 & 0.0154 & 0.7423 & 0.0080 & 0.0987 & 0.02207 & 0.39884 \\
\hline \multirow{3}{*}{30} & 20 & 0.0001 & 0.6543 & 1.7250 & 0.2956 & 0.5800 & 0.71072 & 5.57644 \\
\cline { 2 - 9 } & 25 & 0.0003 & 0.4898 & 1.8034 & 0.1872 & 0.7248 & 0.46261 & 4.73050 \\
\cline { 2 - 9 } & 30 & 0.0000 & 0.0142 & 0.7340 & 0.0065 & 0.0845 & 0.01860 & 0.34159 \\
\hline
\end{tabular}

\subsection{Data analysis}

In this subsection we provide a data analysis to see how the mixture MW distribution works in practice. This data is from Ahmad and Ali [25] and its elements are shown as follows

$0.03,012,0.22,0.35,0.73,0.79,1.25,1.41,1.52,1.79,1.8,1.94,2.38,2.4,2.87,2.99,3.14,3.17$, 4.72 and 5.09 
In addition to the MW mixture model, we have used Weibull mixture model.

Table4: The associated K-S values

\begin{tabular}{|c|c|c|}
\hline The model & MLE of the parameter(s) & $\mathrm{K}-\mathrm{S}$ \\
\hline $\begin{array}{c}\text { Mixture of two } \\
\mathrm{W}(\alpha, \beta) \text { distributions }\end{array}$ & $\begin{array}{c}\hat{\alpha}_{1}=0.68114, \hat{\alpha}_{2}=2.03714, \\
\hat{\beta}_{1}=1.53169, \hat{\beta}_{2}=2.19509, \\
\hat{p}=0.601892\end{array}$ & 0.0993674 \\
\hline $\begin{array}{c}\text { Mixture of two } \\
\text { MW }(\alpha, \beta, \gamma) \\
\text { distributions }\end{array}$ & $\begin{array}{c}\hat{\alpha}_{1}=0.339943, \hat{\alpha}_{2}=0.748108, \\
\hat{\beta}_{1}=0.434762, \hat{\beta}_{2}=0.771195,\end{array}$ & 0.0604594 \\
\hline
\end{tabular}

It seems from the results shown in Table 4 that the $\operatorname{MW}(\alpha, \beta, \gamma)$ mixture model fits the data better than the other mixture model. Based on the first 10 observations which represents a type-II censored sample of size 10 from the original real sample, the estimates of the MW mixture model parameters are $\hat{\alpha}_{1}=0.31901, \hat{\alpha}_{2}=0.71532, \hat{\beta}_{1}=0.40713, \hat{\beta}_{2}=0.79012, \hat{\gamma}_{1}=2.93207, \hat{\gamma}_{2}=$ $0.35981, \hat{p}=0.779069$.

\subsection{Concluding remarks}

In most cases, observe the following:

1. We choose the values of the population parameters to give us bathtub of hazard rate.

2. For fixed sample size $n$ and by increasing the censoring values fixed $t_{0}$ and $r$, we get smaller MSE's.

3. For fixed $t_{0}$ and $r$ and by increasing the sample size $n$, we get smaller MSE's.

4. The largest values of $t_{0}$ and $r$ in each case represent the complete sample case.

\section{References}

1. Weibull, W. (1939). A statistical theory of the strength of material. Ingeniors Vetenskaps Akademiens Handligar Report No. 151, Stockholm.

2. Weibull, W.(1939). The phenomenon of rupture in solids. Ingeniors Vetenskaps Akademiens Handligar Report No. 153, Stockholm.

3. Berrettoni, J.A. (1964). Practical Applications of the Weibull Distribution. Industrial Quality Control 21, 71-79.

4. Mudholkar, G. S., Srivastava, D. K. and Kollia, G.D.(1996). A generalization of the Weibull Distribution with Application to the Analysis of Survival Data. J. Amer. Statist. A ssoc., 91, 1575-1583.

5. Nordman, D. and Meeker, W.(2002). Weibull Prediction Intervals for a Future Number of Failures. Technometrics, 44, 15-23.

6. Nadarajah, S. and Kotz, S.( 2006). On The Product And Ratio Of Gamma And Weibull Random Variables. Cambridge University Press, 22(02), 338- 344.

7. Lieblein, J. and Zelen, M.(1956). Statistical Investigation of the Fatigue Life of Deep Groove Ball Bearings. J. Res. Nat. Bur.Std., 57, 273-315.

8. Kao, J.H.K.(1959). A graphical Estimation of Mixed Weibull Parameters in Life-testing Electron tubes. Technometrics, 4, 309-407. 
9. Mann, N.R.(1968). Results on Statistical Estimation and Hypothesis Testing with Application to the Weibull and Extreme Value Distribution. Aerospace Research Laboratories, Wright-Patterson Air Force Base, Ohio.

10. Nelson, W.B.(1972). Graphical Analysis of Accelerated Life Test Data with the Inverse Power Law Model. IEE Transaction on Reliability, R-21, 2-11.

11. Whittemore, A. and Altschuler, B. (1976). Lung Cancer Incidence in Cigarette Smokes: Further Analysis of the Doll and Hill's Data for British physicians. Biometrics, 32, 805-816.

12. Calabria, R. and Pulcini, G.(1989). Confidence Limits for Reliability and Tolerance Limits in the Inverse Weibull Distribution. Reliability Engineering and System Safety, 24, 77-85.

13. Mittnik, S. and Rachev, S.T.(1993). Modeling Asset Returns with Alternative Stable Distribution. Economic Reviews, 12, 261-330.

14. Jiang, R., Zuo, M.J. and Li, H.X.(1999). Weibull and Inverse Weibull Mixture Models Allowing Negative Weights. Reliability Engineering and System Safety, 66(3), 227-234.

15. Aboeleneen, Z.A.(2010). Inference for Weibull Distribution under Generalized Order Statistics. Math. Comput. in Simul., 81, 26-36.

16. Rinne, H. (2009). The Weibull Distribution: A Handbook. Chapman and Hall.

17. Lai, C.D. , Xie, M. and Murthy, D.N.(2003). A modified Weibull distribution. IEEE Trans. Reliab., 52, 33-37.

18. Sultan, K. S.(2007). Record Values from the Modified Weibull Distribution and Applications. International Mathematical Forum, 2( 41), 2045 - 2054.

19. Vasile, P., Eugenia, P. and Alina, C.(2010). Bayes estimators of modified Weibull distribution parameters using Lindley's approximation. WSEAS Transactions on Mathematics, 9, 539-549.

20. Lai, C. D. , Moore, T. and Xie, M.(1998). The beta integrated model. In Proc. Int. Workshop on Reliability Modeling and Analysis-From Theory to Practice, 153-159.

21. Johnson, N.L., Kotz, S. and Balakrishnan, N. (1995). Continuous Univariate Distributions. Vol. 2, Second edition, Wiley, New York.

22. Lawless, J. F. (1982). Statistical models and methods for lifetime data. Wiley, New York.

23. Dempster, A. R., Laird, N.M. and Rubin, D.B.(1977). Maximum likelihood from incomplete data via EM algorithm. J. Royal Statist. Soc., B, 39, 1-38.

24. McLachlan, G. J. and Krishnan, T.(1997). The EM Algorithm and Extensions. Wiley, New York.

25. Ahmad, M. R. and Ali A. S.(2009). Combining Two Weibull Distributions Using a Mixing Parameter. European Journal of Scientific Research, 31(2), 296-305. 